\title{
Graphene-Supported Silver Nanoparticles with High Activities toward Chemical Catalytic Reduction of Methylene Blue and Electrocatalytic Oxidation of Hydrazine
}

\author{
Chengen $\mathrm{He}^{1}$, Zixiu Liu ${ }^{1}$, Yun Lu ${ }^{1}$, Leping Huang ${ }^{2, *}$, and Yingkui Yang ${ }^{1, *}$ \\ ${ }^{1}$ School of Materials Science and Engineering, Hubei University, Wuhan 430062, China \\ ${ }^{2}$ School of Materials Science and Engineering, Wuhan Textile University, Wuhan 430200, China \\ *E-mail: 1phuang@wtu.edu.cn, ykyang@hubu.edu.cn
}

doi: $10.20964 / 2016.11 .72$

Received: 27 June 2016 / Accepted: 7 September 2016 / Published: 10 October 2016

\begin{abstract}
Reduced graphene oxide (RGO)/silver nanoparticle (Ag NP) composites (Ag/RGO) were prepared by a two-step route that involves chelating Ag NPs onto GO in the presence of $N, N$-dimethylformamide, followed by reduction with sodium borohydride. Ag NPs with an average dimeter of $5.6 \mathrm{~nm}$ were found to be uniformly distributed on the surface of RGO sheets, and the resulting Ag/RGO composite exhibits good chemical catalytic behavior toward reduction of methylene blue and high electrocatalytic activity toward electrooxidation of hydrazine.
\end{abstract}

Keywords: Reduced graphene oxide, silver nanoparticles, chemical catalysis, electrocatalysis.

\section{$\underline{\text { FULL TEXT }}$}

(C) 2016 The Authors. Published by ESG (www.electrochemsci.org). This article is an open access article distributed under the terms and conditions of the Creative Commons Attribution license (http://creativecommons.org/licenses/by/4.0/). 